\title{
Hegemonia e estratégia socialista
}

LACLAU, Ernesto; MOUFFE, Chantal. Hegemonia e estratégia socialista: por uma política democrática radical. São Paulo: Intermeios, 2015.

Kamila Lima do Nascimento*

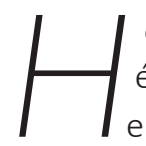
egemonia e estratégia socialista: por uma política democrática radical é, sem dúvida, a mais importante obra dos teóricos políticos Ernesto Laclau e Chantal Mouffe. Foi originalmente publicada em inglês, em 1985 - sob o título Hegemony and socialist strategy: towards a radical democratic -, e, somente em 2015, 30 anos após o lançamento, recebeu a sua versão em língua portuguesa. O atraso da tradução para o português reflete a utilização ainda incipiente dos autores no Brasil, apesar de sua importância incontestável em nível mundial onde os mesmos já tiveram seus livros traduzidos para mais de 20 idiomas.

Ernesto Laclau, falecido em 2014, deixou um extenso e importante legado para a teoria política ${ }^{1}$, sendo mesmo considerando um dos nomes mais proeminentes deste campo. Embora sua carreira tenha se iniciado em Buenos Aires, seu país de origem, realizou a maior parte de sua produção na Universidade de Essex, Inglaterra, onde se radicou, concluiu seu doutorado e permaneceu até sua morte. Também foi nesta universidade que fundou, em 1982, a Escola Pós-Estruturalista de Análise do Discurso de Essex, em funcionamento até os dias de hoje, e que acolhe estudantes do mundo todo com interesse no desenvolvimento de análises nesta área. Chantal Mouffe possui uma carreira igualmente produtiva, tendo lecionado em diversas universidades do mundo todo e escrito mais de uma dezena de livros, principalmente voltados ao tratamento do tema da democracia.

Em termos de influências intelectuais, Laclau e Mouffe fizeram parte da escola marxista até a década de 1970, quando então passaram a criticar os fundamentos desta corrente e aderiram aos pressupostos da escola pós-estruturalista, especialmente a concepção antiessencialista do discurso e sua centralidade. Eles acreditavam que o projeto de esquerda, depois de um período rico e criativo na década de 1960, havia entrado em crise em meados dos anos 1970, crise que só viria a se aprofundar a partir de então. Ela advinha de uma avalanche de mutações históricas de uma sociedade que passou a ser globalizada e governada pela informação e revolveram o terreno em que as verdades do marxismo foram constituídas.

\author{
* Doutoranda em \\ ciência política \\ na Universidade \\ Federal de Pelotas. \\ $<$ kamilado \\ nascimento@gmail. \\ com>. \\ 1. Apesar de se \\ considerar um \\ teórico político, os \\ trabalhos de Laclau \\ são utilizados em \\ diversos outros \\ campos acadêmicos.
}


Apesar das críticas, não interessava aos autores simplesmente abandonar a tradição da qual faziam parte. Eles acreditavam que o marxismo clássico podia ajudar a formar o pensamento de uma nova esquerda através do legado de alguns de seus conceitos, desde que suas condições de possibilidade fossem revistas e seus pressupostos essencialistas fossem abandonados. Por isso, ao invés romperem completamente com esta escola, os autores resolveram tomar o caminho da desconstrução e da reativação da herança marxista a partir de dentro, o que lhes rendeu o rótulo de pós-marxistas.

Hegemonia e estratégia socialista é o grande marco dessa virada teórica na carreira dos autores. É nesta obra que eles desconstroem a teoria marxista e, na sequência, a partir da reativação de alguns de seus conceitos, criam sua ontologia própria, a teoria do discurso, que, de acordo com os próprios autores, apresenta ferramentas teóricas mais adequadas para pensar o social como este se apresenta na contemporaneidade. O livro está dividido em quatro capítulos e todos têm como fio condutor o conceito de hegemonia, reativado da teoria marxista e sem dúvida o mais central na teoria dos autores.

Os dois primeiros capítulos são respectivamente intitulados "Hegemonia: a genealogia de um conceito" e "Hegemonia: a difícil emergência de uma nova lógica política", ambos dedicados ao estabelecimento da reconstituição histórica do conceito de hegemonia no âmbito da tradição iniciada por Marx. Esta é a razão pela qual os autores percorrem grande parte das obras de autores centrais para a teoria marxista tais como, Rosa Luxemburgo, Kautsky, Bernstein, Sorel, Lenin, Gramsci, entre outros, para traçar a trajetória do conceito em suas múltiplas construções e reconstruções ao longo da história do marxismo.

Os autores destacam três fases principais do desenvolvimento desse conceito: o surgimento na social-democracia russa, quando emerge como resposta socialista ao hiato que havia sido aberto no horizonte explicativo da categoria da "necessidade histórica"; seu desenvolvimento com o leninismo, ao adquirir um caráter eminentemente político, quando o conceito é instado a preencher outra contingência, entre a constituição de classe no campo das relações de produção e sua a presença no campo político, onde os interesses das classes deveriam ser representados; e, por fim, com Gramsci, quando

[...] o termo adquire um novo tipo de centralidade, que transcende seu uso tático ou estratégico: "hegemonia" se torna o conceito-chave na compreensão da própria unidade existente numa formação social concreta (p. 58). 
A expansão dos significados atribuídos ao conceito de hegemonia está - segundo os autores - diretamente relacionada à expansão da "lógica do contingente" dentro da teoria marxista, ou seja, com a rejeição progressiva da categoria de necessidade histórica e a aceitação da indeterminação do social. Contudo, para Laclau e Mouffe nenhum dos autores revisados conseguiu romper completamente com o essencialismo daquela teoria, especialmente no que tange à questão do reducionismo economicista.

No terceiro capítulo - "Além da positividade do social: antagonismos e hegemonia" -, os autores mostram uma nova possibilidade para o uso do conceito de hegemonia e apresentam as demais categorias e conceitos de sua teoria, e, por essa razão, trata-se certamente do capítulo mais importante para os leitores interessados em conhecer o trabalho dos autores. De acordo com eles, a hegemonia deve ser entendida como operação política de construção do social, ela ocorre quando uma particularidade, através da articulação contingente, assume a tarefa de representar várias outras particularidades como universal compartilhado.

De forma bastante resumida podemos pensar esta operação com o auxílio de um exemplo. Imaginemos uma situação de extrema desordem: queda abrupta e radical de um governo, por exemplo. Em algum momento, algum tipo de ordem será requerido para que a administração do social seja possível, já que o mundo sem qualquer tipo de estrutura social seria o mundo sem sentido e destituído de ordem. Várias propostas serão apresentadas como a melhor possível para ocupar o espaço da ordem. Elas estão a princípio dispersas no que Laclau e Mouffe chamam de campo da discursividade e são a rigor apenas particularidades. Em algum momento - que não se pode determinar - uma dessas propostas - que também é impossível prever a priori - emergirá e, sem deixar de ser particular, tomará para si a tarefa de representar um universal compartilhado com as demais propostas, iniciando uma operação de articulação de equivalência contra outras propostas da agenda. A proposta que conseguir agregar em torno de si o maior número de outras propostas será considerada a mais hegemônica ou o discurso mais hegemônico. Ao ocupar o lugar da ordem - de forma precária e contingente - passará a ser considerada a própria ordem e irá estruturar o social e as identidades sociais.

Embora, em princípio, esta operação pareça ser bastante simples ela é, na verdade, bastante complexa e depende de uma série de condições especiais para o seu funcionamento. Uma delas - talvez a mais importante - é que aceitemos que aquilo que os autores chamam de campo discursivo seja exatamente a mesma coisa daquilo que conhecemos por campo do social e logo que aceitemos que todas as práticas sociais sejam práticas discursivas e que as identidades sociais sejam, a partir desta 
perspectiva, discursos. Isso não significa a conversão do campo social em campo linguístico. Discursos aqui não devem ser entendidos como fenômenos relativos estritamente às áreas da fala e da escrita, uma vez que atravessam toda a densidade material do social. Quando os autores falam em campo do discurso, ou em discursos, o que está subentendido é o acolhimento da dimensão simbólica como parte das construções sociais.

Uma segunda categoria absolutamente central na teoria do discurso e que merece destaque é o antagonismo. Esta categoria, também reativada a partir da teoria marxista, diz respeito à experiência do limite do social. Ele não encerra um conteúdo objetivo, o antagonismo é um exterior constitutivo que revela a contingência e a precariedade de toda identidade e objetividade social, já que toda identidade está sempre ameaçada por alguma coisa externa a ela (Howarth, 2000: 106). Entretanto, o antagonismo não apenas limita, mas também constitui as relações sociais e as identidades e é também responsável pela motivação da articulação hegemônica, pois todo discurso é sempre dirigido contra alguém, seu discurso opositor, que é também o que o motivará à articulação.

Apesar de sua fundamental importância, a categoria do antagonismo sofreu diversas críticas. Há de se destacar aquela proferida por Slavoj Zizek - em seu "além da análise do discurso" - para quem os autores mostraram-se sensíveis e admitiram problemas quanto à ambiguidade da categoria. Em sua segunda obra pós-estruturalista - New reflexions of the revolution of our time (1990) -, Laclau desenvolve a categoria do deslocamento para substituir o antagonismo a partir das críticas recebidas (Stavrakakis, 2000).

Uma segunda crítica bastante importante contra a categoria de antagonismo quanto ao privilégio do momento da negatividade na construção das identidades sociais foi desenvolvida Aletta Norval. Ela questiona se somente a partir da relação "amigo/ inimigo" é possível a formação das identidades, pois a positividade estaria ausente da discussão dos autores que privilegiam apenas as relações antagônicas diferenciais da identidade (Norval, 2000: 223).

Há outros vários conceitos e categorias importantes no terceiro capítulo à espera dos leitores para serem desveladas. É o caso dos pontos nodais, trazidos da psicanálise de Lacan, ideologia reconstruída também do marxismo após um "choque" com o real lacaniano; da categoria do sujeito, completamente diferente tanto daquele do humanismo quanto do marxismo e inteiramente assentado no pós-estruturalismo; das lógicas da diferença e da equivalência que explicam como o social é estruturado politicamente e outros tantos insights interessantes. 
Por fim, no último capítulo - "Democracia radical e plural" -, Laclau e Mouffe apresentam uma série de sugestões para um futuro projeto político dedicado à esquerda. Para os autores, a crise em que se encontrava a teoria marxista não se restringia ao campo teórico, mas se refletia no campo das práticas políticas, e logo, este também precisava ser socorrido. Segundo Laclau e Mouffe, a esquerda política estaria sistematicamente se redefinindo enquanto centro e esquecendo os projetos de mudanças mais radicais. Defenderam até mesmo que a esquerda elaborasse uma alternativa de credibilidade à ordem neoliberal, ao invés de simplesmente tentar administrá-la de forma mais humana.

Embora os autores não ofereçam uma proposta positiva ou normativa, o projeto de democracia radical e plural oferece no mínimo um ponto de partida segundo o qual um projeto de esquerda deveria ser pensado. Segundo eles, um novo projeto para a esquerda deve ter por missão a construção de um novo indivíduo. Este deveria ser diferente tanto daquele construído pelo liberalismo, pautado no individualismo possessivo, quanto daquele construído pelo socialismo tradicional, portador de uma identidade classista. Deve se fundar na negação da essência do social e na afirmação da contingência como constitutiva deste. Também é preciso que o projeto parta da aceitação do antagonismo como constitutivo da política, e da rejeição da ideia de um argumento racional não excludente (crítica diretamente direcionada ao projeto habermasiano). Para eles, conflito e divisão

[...] não são nem distúrbios que infelizmente não podem ser eliminados, nem impedimentos empíricos que impossibilitam a plena realização de uma harmonia inatingível porque nunca seremos capazes de deixar nossas particularidades inteiramente de lado (p. 45).

O sucesso de um novo projeto depende - segundo os autores - do reconhecimento adequando do funcionamento das construções hegemônicas - como eles as constroem - e da escolha certa da estratégia política que se deveria tomar. Ele não pode pautar-se em uma "estratégia de oposição", pois um projeto hegemônico que não apresente uma proposta viável de "reconstrução de áreas específicas da sociedade, tem sua capacidade de agir hegemonicamente excluída de saída" (p. 279). Ao invés disso, deve basear-se em uma "estratégia de construção de uma nova ordem" e constituir um projeto pautado em um conjunto de propostas de organização positiva do social" (p. 279).

Mas, afinal, qual a relação entre hegemonia e democracia radical e plural e por que pensar em termos de relações hegemônicas é tão importante para Laclau e Mouffe? Para os autores, mover-se pelo campo da hegemonia não é uma opção, mas o simples reconhecimento da natureza das relações sociais na contemporaneidade. 
De acordo com eles, a partir da revolução democrática, a divisão do espaço político passou a ser fragmentada e a complexidade do social se expandiu, bem como a pluralidade peculiar das sociedades industriais tornaram as divisões sociais borradas. Desde então o social não pode mais ser dividido em dois campos radicais e as construções sociais passaram a depender de articulações hegemônicas. Dessa forma, o imaginário democrático é o campo próprio das práticas hegemônicas e estas, de acordo com os autores, são muito mais libertárias e ambiciosas do que o projeto marxista clássico. O mundo é menos dado, e por isso sempre há uma oportunidade0 de recriá-lo infinitamente.

A democracia abre o espaço para a liberdade de criação, embora não garanta que a direção tomada será sempre progressista. Por isso mesmo, é preciso que a esquerda tome a direção dos projetos e é somente pelo reconhecimento do caráter aberto do social - quando o essencialismo da totalidade e dos elementos é rejeitado - que o potencial da hegemonia como ferramenta de análise política torna-se claro.

\section{Referências}

HOWARTH, D. Discourse. Buckingham: Open University Press, 2000.

NORVAL, A. Trajectories of future research in discourse theory. In: HOWARTH, D.; NORVAL, A. J.; STAVRAKAKIS, Y. (Eds.). Discourse theory and political analysis: identities, hegemonies and social change. Manchester: Manchester University Press, 2000.

STAVRAKAKIS, Y. Laclau with Lacan: comments on the relation between discourse theory and Lacanian psychoanalysis. In: ZIZEK, S. (Ed.). Jacques Lacan: critical evaluations in cultural theory. v. III: "Society, politics, ideology". London: Routledge, 20030. 